\title{
Optimasi Dosis Koagulan Untuk Pengolahan Air Sungai Suko
}

\section{Optimization of Coagulant Dosage for Suko River Water Treatment}

\author{
Syarifah Aini $^{*}$, Hari Dwi Wahyudia ${ }^{\mathrm{a}}$ Kukuh Priyono ${ }^{\mathrm{a}}$ \\ a Jurusan Teknik Sipil, Universitas Widya Dharma Klaten \\ Jl. Ki Hajar Dewantara, Klaten 57438, Jawa Tengah, Indonesia
}

\section{Artikel histori : \\ Diterima 26 Februari 2021 Diterima dalam revisi 30 Maret 2021 Diterima 6 April 2021 Online 13 April 2021}

\begin{abstract}
ABSTRAK: Sungai Suko, Desa Drono, Kecamatan Ngawen, Kabupaten Klaten, terletak di dekat pemukiman penduduk dan pabrik tahu, kemungkinan air mengalami pencemaran cukup tinggi, yang disebabkan oleh limbah pabrik dan rumah tangga. Air sungai ini dapat diolah menjadi air bersih dengan proses koagulasi dengan metode Jar Test menggunakan koagulan tawas, Poly Aluminium Chloride (PAC) dan kaporit. Tujuan dari penelitian adalah untuk mengetahui dosis optimum koagulan dalam pengolahan air sungai Suko menjadi air bersih dengan metode Jart test dan mengetahui koagulan mana yang paling cocok digunakan dalam mengolah air sungai Suko menjadi air bersih. Penelitian ini menggunakan percobaan Jar Test untuk menentukan dosis koagulan optimum dalam mengolah air sungai Suko menjadi air bersih. Sampel air sebelum percobaan diuji kualitasnya yang meliputi parameter fisik yaitu suhu, warna, bau, kekeruhan dan parameter kimia yaitu $\mathrm{Fe}$, kesadahan, $\mathrm{CO}_{2}$, alkalinitas, $\mathrm{pH}$, COD, BOD, kemudian hasil percobaan akan diketahui tingkat kejernihan airnya. Hasil penelitian menunjukkan kadar tawas optimum percobaan adalah 120 ppm yaitu dengan menambahkan $6 \mathrm{~mL}$ tawas ke dalam $500 \mathrm{~mL}$ air, kadar PAC optimum percobaan adalah 200 ppm yaitu dengan menambahkan $10 \mathrm{~mL}$ Poly Aluminium Chloride ke dalam $500 \mathrm{~mL}$ air, dan kadar kaporit optimum percobaan adalah 160 ppm yaitu dengan menambahkan $8 \mathrm{~mL}$ kaporit ke dalam $500 \mathrm{~mL}$ air.
\end{abstract}

Kata Kunci: Jar Test; tawas; PAC; kaporit; kejernihan

\begin{abstract}
Sungai Suko, Drono village, Ngawen sub-district, Klaten district, is located near residential area and tofu factory, the possibility of water contamination is quite high, which is caused by household waste. This river water can be processed into clean water by a coagulation process of the Jar Test method using coagulant alum, PAC and chlorine. The purpose of this study was to determine the optimum dose of coagulant in processing Suko river water into clean water using the Jar test method and knowing which coagulant is most suitable for processing the Suko river water into clean water. This research method is to use the Jar Test experiment to determine the optimum coagulant dose in processing Suko river water into clean water. The quality of the water samples before the experiment were tested which included the physical parameters, i.e. temperature, color, odor, and turbidity, also the chemical parameters, i.e. Fe, hardness, $\mathrm{CO}_{2}$, alkalinity, $\mathrm{pH}, \mathrm{COD}, \mathrm{BOD}$, then the experimental results will determine the level of water clarity. The results showed that the optimum alum content in the experiment was $120 \mathrm{ppm}$ by adding $6 \mathrm{~mL}$ of alum to $500 \mathrm{~mL}$ of water, the optimum level of PAC in the experiment is $200 \mathrm{ppm}$ by adding $10 \mathrm{~mL}$ of PAC to $500 \mathrm{~mL}$ of water, and the optimum chlorine level in the experiment is $160 \mathrm{ppm}$ by adding $8 \mathrm{~mL}$ of chlorine to $500 \mathrm{~mL}$ of water.
\end{abstract}

Keywords: Jar Test; alum; PAC; kaporit; clarity

\section{Pendahuluan}

Air adalah kebutuhan yang sangat penting bagi manusia, begitu juga dengan seluruh mahluk hidup yang ada di bumi ini. Manusia melakukan berbagai upaya untuk memenuhi kebutuhan air bersih untuk dikonsumsi, baik untuk air minum, maupun untuk kebutuhan rumah tangga lainnya (Usman, 2000).

Beberapa sumber air yang tersedia, penduduk Indonesia sebagian besar menggunakan air permukaan terutama air sungai dan air sumur. Berdasarkan penelitian yang dilakukan Kementrian Lingkungan Hidup (KLH) pada

*Corresponding Author: 0272-322363 Fax. 0272-323288

Email: aini07931@gmail.com 
tahun 2014 bahwa $70-75 \%$ sungai di 33 provinsi Indonesia telah tercemar. Polutan dominan yang mencemari sungai berasal dari limbah domestik yang berasal dari rumah tangga. Untuk meningkatkan kebutuhan dasar masyarakat mengenai kebutuhan air bersih, maka perlu diterapkan teknologi yang sesuai dengan tingkat penguasaan teknologi dalam masyarakat itu sendiri. Salah satu alternatif yakni menggunakan teknologi pengolahan air sederhana dengan mengolah air sungai menjadi air bersih dengan proses koagulasi (Sutrisno, 2010).

Wathoni et al. (2020) melakukan penelitian tentang "Pengaruh Penambahan Flokulan dan Koagulan Menggunakan Metode Jar Test terhadap Kualitas Air Baku”, menyimpulkan bahwa penambahan flokulan dan koagulan dengan metode Jar Test ini dapat menurukan kadar pH 10\% dan Turbidity 95\% dalam air baku. Demikian juga penelitian yang dilakukan oleh Budiman et al., (2008) tentang "Kinerja Koagulan Poly Alumunium Chloride (PAC) dalam Penjernihan Air Sungai Kalimas Surabaya" menghasilkan kesimpulan penelitian terbaik pada kadar PAC 50 ppm, waktu pengadukan 10 menit, dan kecepatan pengadukan $100 \mathrm{rpm}$ di mana nilai turbiditas hasil penjernihan air sungai 0,7 NTU, TSS 96,4 mg/L, pH larutan 6,53, dan TDS-mg/L.

Merujuk kedua jurnal di atas, penelitian ini dilakukan dengan mengambil sampel air dari Sungai Suko, Desa Drono, Kecamatan Ngawen, Kabupaten Klaten. Lokasi sungai ini terletak di dekat jalan raya, pemukiman penduduk dan pabrik tahu, air sungai mengalami pencemaran sebagai akibat dari limbah rumah tangga dan limbah pabrik tahu, ditunjukkan dengan hasil uji sampel awal COD 63,5 mg/L dan BOD 7, $42 \mathrm{mg} / \mathrm{L}$.

Pada penelitian ini digunakan koagulan tawas, kaporit dan PAC untuk mengolah air sungai Suko menjadi air bersih dengan proses koagulasi yang menggunakan metode Jar Test. Jar test adalah suatu metode pengujian untuk mengetahui kemampuan suatu koagulan dan menentukan kondisi operasi (dosis) optimum pada proses penjernihan air dan air limbah. Metode jar test mensimulasikan proses koagulasi dan flokulasi untuk menghilangkan padatan tersuspensi (suspended solid) dan zat-zat organik yang dapat menyebabkan masalah kekeruhan, bau dan rasa (Husaini et al., 2018).

Rumusan masalah penelitian ini adalah bagaimana pengolahan air sungai dengan metode Jart Test menjadi air bersih serta koagulan apa yang paling cocok untuk digunakan dalam mengolah air Sungai Suko menjadi air bersih. Koagulan yang digunakan adalah tawas, kaporit dan PAC, karena jenis koagulan ini sering digunakan dan banyak beredar di pasaran, serta ramah lingkungan (Eckenfelder and Wesley, 2000).

Batasan masalah dalam penelitian ini adalah pengolahan air sungai Suko menjadi air bersih hanya sampai pengolahan dengan menggunakan metode Jar Test, Koagulan yang digunakan adalah tawas, kaporit dan poly aluminium chloride (PAC).

Tujuan dari penelitian adalah untuk mengetahui dosis optimum koagulan dalam pengolahan air sungai Suko menjadi air bersih dengan metode Jart Test dan mengetahui koagulan mana yang paling cocok digunakan dalam mengolah air sungai Suko menjadi air bersih.

Penelitian ini diharapkan dapat memberikan kontribusi kepada khasanah ilmu pengetahuan tentang pengolahan air sungai menjadi air bersih dengan jalan proses koagulasi dengan metode Jar Test.

Kebaruan dalam penelitian ini adalah terletak pada sampel air baku yang mempunyai parameter kualitas air deangan COD 63,5 mg/L dan BOD 7,42 mg/L, dapat diolah menjadi air bersih dengan metode Jar Test, dan mencari koagulan yang cocok untuk mengolah air baku tersebut.

\section{Metode Penelitian}

\subsection{Alat, Bahan dan Tempat}

Alat dalam penelitian ini adalah neraca analitik, flokulator. Bahan yang digunakan adalah air sungai Suko, PAC, tawas, kaporit, aquadest, kertas $\mathrm{pH}$ merk universal. Percobaan penelitian ini dilakukan di laboratorium Penyehatan dan Lingkungan Universitas Sebelas Maret Surakarta.

\subsection{Pengambilan Sampel}

Pengambilan air sampel berlokasi di sungai Suko, desa Drono, kecamatan Ngawen, kabupaten Klaten. Lokasi sungai Suko ini terletak di dekat jalan raya, pemukiman penduduk dan pabrik tahu, jadi kumungkinan air mengalami pencemaran cukup tinggi. Penyebab lain di antaranya limbah rumah tangga, baik limbah organik maupun limbah anorganik.

Sampel air diambil dari lokasi menggunakan jerigen air yang berjumlah 2 buah ( \pm 10 liter) pada bulan Januari 2019. Pengambilan dilakukan dari permukanan air dengan hatihati sehingga kondisi air yang diambil sesuai dengan kondisi air di lapangan. Metode yang digunakan adalah:

a. Menjaga agar endapan di dasar sungai tidak ikut terbawa.

b. Menggunakan jerigen yang bersih dan tidak mengandung zat-zat kimia yang mudah larut, hal tersebut dilakukan untuk menghindari kesalahan analisis.

\subsection{Persiapan Bahan dan Desain Percobaan}

Setelah air diambil dari sungai Suko maka dilakukan uji sampel dengan beberapa parameter kualitas air antara lain uji fisika yaitu suhu, warna, bau, kekeruhan, dan uji kimia yaitu $\mathrm{Fe}$, kesadahan total, $\mathrm{CO}_{2}$, alkalinitas, $\mathrm{pH}, \mathrm{COD}$ dan BOD.

Langkah percobaan dimulai dengan melakukan uji Jar Test dengan menambahkan koagulan tawas yaitu pertama adalah mengisi enam buah gelas beker $600 \mathrm{~mL}$ masing masing dengan $500 \mathrm{~mL}$ air sungai kemudian mengukur $\mathrm{pH}$ nya dengan kertas $\mathrm{pH}$. Kedua adalah memasukkan larutan tawas ke dalam masing-masing gelas beker sebanyak $(4,6$, $8,10,12,14) \mathrm{mL}$, kemudian dilakukan pengadukan cepat selama 1 menit, setelah itu pengadukan lambat selama 5 menit dan mendiamkannya selama 10 menit sehingga terbentuk endapan. Ketiga adalah membuat tabel kadar tawas, $\mathrm{pH}$ dan tingkat kejernihan. Keempat adalah menghitung dosis optimum koagulan yang bisa memberikan endapan terbanyak tiap 1 liter air. 


$$
\begin{aligned}
& \text { Dosis optimum koagulan }=(\mathrm{b} \times \mathrm{a}) / \mathrm{c} \\
& \mathrm{a}=\operatorname{volume} \text { air sampel }(\mathrm{mL}) \\
& \mathrm{b}=\text { volume koagulan }(\mathrm{mL}) \\
& \mathrm{c}=\text { dosis koagulan }(\mathrm{g} / \mathrm{L})(\mathrm{SNI}, 2000)
\end{aligned}
$$

Percobaan dengan koagulan PAC dan kaporit, langkah percobaannya sama dengan langkah-langkah percobaan dengan uji koagulan tawas, dengan hasil pengujian yang berbeda.

\section{Hasil dan Pembahasan}

\subsection{Pengujian Sampel Air Sungai Suko}

\begin{tabular}{|c|c|c|c|}
\hline Parameter & $\begin{array}{c}\text { Sampel } \\
\text { Air Baku }\end{array}$ & $\begin{array}{c}\text { Standar Permenkes RI } \\
\text { No.416/MENKES/PER/ } \\
\text { IX/1990 }\end{array}$ & Keterangan \\
\hline \multicolumn{4}{|l|}{ Uji Fisika } \\
\hline $\begin{array}{l}\text { Suhu } \\
\text { Warna } \\
\text { Bau } \\
\text { Kekeruhan }\end{array}$ & $\begin{array}{l}24^{\circ} \mathrm{C} \\
\text { Coklat } \\
\text { Amis } \\
\text { Agak Keruh }\end{array}$ & $\begin{array}{l}27-28^{\circ} \mathrm{C} \\
\text { Tidak Bewarna } \\
\text { Tidak Berbau } \\
\text { Jernih }\end{array}$ & $\begin{array}{l}\text { Tidak Memenuhi } \\
\text { Tidak Memenuhi } \\
\text { Tidak Memenhi } \\
\text { Tidak Memenuhi }\end{array}$ \\
\hline \multicolumn{4}{|l|}{ Uji Kimia } \\
\hline $\begin{array}{l}\text { Fe } \\
\text { Kesadahan } \\
\text { Total }\end{array}$ & $\begin{array}{l}0 \mathrm{mg} / \mathrm{L} \\
5,6^{\circ} \mathrm{D}\end{array}$ & $\begin{array}{l}0,0-0,1 \mathrm{mg} / \mathrm{L} \\
\text { Maks. } 28^{\circ} \mathrm{D}\end{array}$ & $\begin{array}{l}\text { Memenuhi } \\
\text { Memenuhi }\end{array}$ \\
\hline $\begin{array}{l}\mathrm{CO}_{2} \\
\text { Alkalinitas }\end{array}$ & $\begin{array}{l}4 \mathrm{mg} / \mathrm{L} \\
87 \mathrm{mg} / \mathrm{L}\end{array}$ & $\begin{array}{l}\text { Maks. } 10 \mathrm{mg} / \mathrm{L} \\
\text { Maks. } 500 \mathrm{mg} / \mathrm{L}\end{array}$ & $\begin{array}{l}\text { Memenuhi } \\
\text { Memenuhi }\end{array}$ \\
\hline $\begin{array}{l}\mathrm{pH} \\
\mathrm{COD} \\
\mathrm{BOD}\end{array}$ & $\begin{array}{l}6 \\
63,2 \mathrm{mg} / \mathrm{L} \\
7,42 \mathrm{mg} / \mathrm{L}\end{array}$ & $\begin{array}{l}5,5-8,5 \\
\text { Maks } 12 \mathrm{mg} / \mathrm{L} \\
\text { Maks } 6 \mathrm{mg} / \mathrm{L}\end{array}$ & $\begin{array}{l}\text { Memenuhi } \\
\text { Tidak Memenuhi } \\
\text { Tidak Memenuhi }\end{array}$ \\
\hline
\end{tabular}

Hasil pengujian awal air sungai Suko dapat dilihat pada Tabel 1.

Tabel 1. Hasil pengujian sampel air Sungai Suko

Tabel 1 menunjukkan bahwa beberapa paramater kimia sudah memenuhi standar baku mutu air sungai yaitu $\mathrm{pH}$, kesadahan total, $\mathrm{CO}_{2}$ dan $\mathrm{Fe}$ dan yang belum adalah $\mathrm{COD}$, BOD. Sedangkan parameter fisika untuk suhu, warna, bau, kekeruhan belum memenuhi baku mutu air sungai sesuai Permenkes RI No.416/MENKES/PER/IX/1990, maka air sungai Suko perlu diolah terlebih dahulu menggunakan proses koagulasi dengan metode Jar Test.

\subsection{Pengujian Sampel Air Sungai Suko dengan Koagulan Tawas}

Hasil pengujian pengolahan air sungai Suko dengan proses koagulasi dengan koagulan tawas dapat dilihat dalam Tabel 2.

Tabel 2. Hasil pengujian dengan koagulan tawas

\begin{tabular}{lllllll}
\hline Sampel & $\mathbf{1}$ & $\mathbf{2}$ & $\mathbf{3}$ & $\mathbf{4}$ & $\mathbf{5}$ & $\mathbf{6}$ \\
\hline pH awal & 6 & 6 & 6 & 6 & 6 & 6 \\
$\begin{array}{l}\text { Volume } \\
\text { tawas }(\mathrm{mL})\end{array}$ & 4 & 6 & 8 & 10 & 12 & 14 \\
Kejernihan & 2 & 6 & 5 & 4 & 3 & 1 \\
pH akhir & 6 & 6 & 6 & 6 & 6 & 6 \\
\hline
\end{tabular}

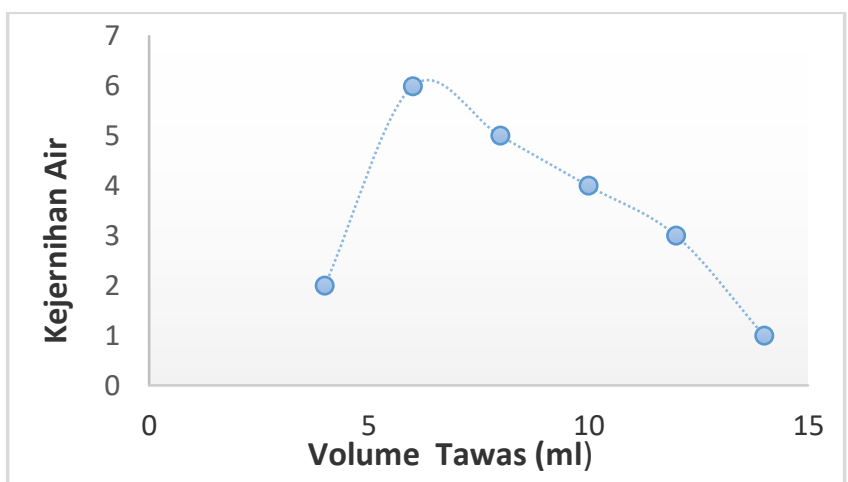

Gambar 1. Hubungan antara kadar tawas dengan kejernihan air.

Keterangan tingkat kejernihan :
1. Sangat keruh
4. Cukup keruh
2. Keruh
3. Agak keruh
5. Jernih
6. Sangat jernih

Gambar 1 dapat dilihat bahwa dengan penambahan volume tawas $6 \mathrm{ml}$ dihasilkan tingkat kejernihan dengan angka 6 , ini menunjukkan bahwa penambahan koagulan tawas $6 \mathrm{~mL}$ menghasilkan kejernihan air yang maksimal, data ini dapat digunakan untuk menghitung Dosis Tawas Optimum (DTO).

Tawas berfungsi untuk mengendapkan kotoran dengan cara mengikat kotoran terlebih dahulu membentuk gumpan-gumpalan yang akan mengendap di dasar wadah. Jika volume tawas ditambahkan terlalu banyak, maka apabila kotoran yang diikat sudah mengendap seluruhnya, tawas akan menjadi pengotor dalam air tersebut.

Data perhitungan Dosis Tawas Optimum (DTO) Volume air sampel : $500 \mathrm{~mL}$ (a)

Volume tawas : $6 \mathrm{~mL}$

Dosis tawas $\quad: 10 \mathrm{~g} / \mathrm{L}$ (c)

Dosis tawas Optimum (DTO)

$$
\begin{aligned}
& \mathrm{DTO}=\frac{b x c}{a}=\frac{6 m L x 10 g / L}{500 m L}=0,12 \mathrm{~g} / \mathrm{L} \\
& =120 \mathrm{mg} / \mathrm{L}
\end{aligned}
$$

Dari hasil perhitungan kadar tawas optimum percobaan adalah 120 ppm yaitu dengan menambahkan $6 \mathrm{~mL}$ tawas ke dalam $500 \mathrm{~mL}$ air. Ini berarti bahwa dengan menambahkan koagulan tawas lebih dari $6 \mathrm{~mL}$ ke dalam $500 \mathrm{~mL}$ air Sungai Suko akan menyebabkan air menjadi keruh karena kotoran yang diikat sudah mengendap seluruhnya, sedangkan tawas yang berlebih akan menjadi pengotor bagi air tersebut. Hasil penelitian Agung (2006) menjelaskan kondisi terbaik untuk koagulan tawas dicapai pada kosentrasi 200 ppm dengan menambahkan flukolan polielektroilit sebesar $8 \mathrm{~mL}$ per 500 mL sampel air. Hasil percobaan yang dilakukan mendekati dengan hasil penelitian sebelumnya, maka DTO hasil percobaan dianggap dapat dipertanggungjawabkan. 


\subsection{Pengujian Sampel Air Sungai Suko dengan Koagulan PAC}

Untuk hasil pengujian terdapat pada Tabel 3 di bawah ini.

Tabel 3. Hasil pengujian dengan koagulan PAC

\begin{tabular}{lllllll}
\hline Sampel & $\mathbf{1}$ & $\mathbf{2}$ & $\mathbf{3}$ & $\mathbf{4}$ & $\mathbf{5}$ & $\mathbf{6}$ \\
\hline $\mathrm{pH}$ awal & 6 & 6 & 6 & 6 & 6 & 6 \\
$\begin{array}{l}\text { Volume } \\
\text { tawas (mL) }\end{array}$ & 4 & 6 & 8 & 10 & 12 & 14 \\
Kejernihan & 1 & 4 & 5 & 6 & 3 & 3 \\
pH akhir & 6 & 6 & 6 & 6 & 6 & 6 \\
\hline
\end{tabular}

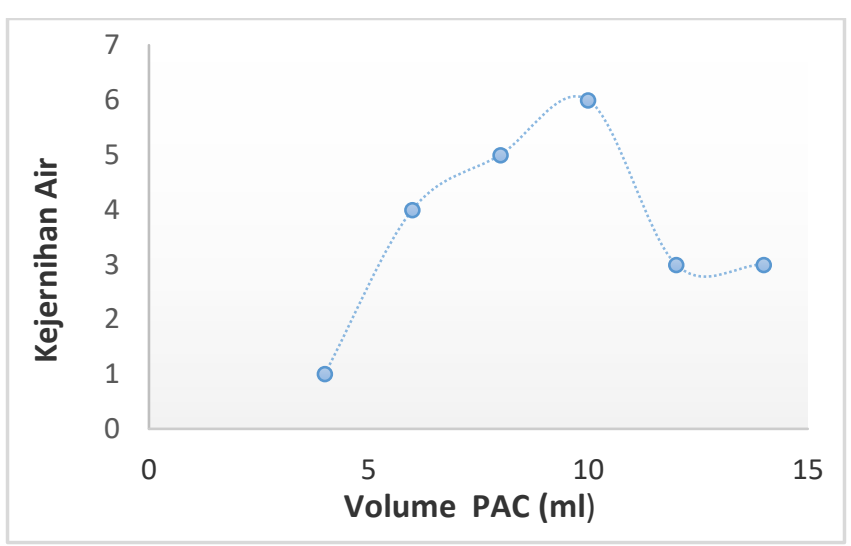

Gambar 2. Hubungan antara kadar PAC dengan kejernihan air

Gambar 2 dapat dilihat bahwa dengan penambahan volume PAC $10 \mathrm{~mL}$ dihasilkan tingkat kejernihan dengan angka 6, ini menunjukan bahwa penambahan koagulan PAC $10 \mathrm{~mL}$ menghasilkan kejernihan air yang maksimal, data ini dapat digunakan untuk menghitung dosis PAC Optimum.

PAC berfungsi untuk mengendapkan kotoran dengan cara mengikat kotoran terlebih dahulu membentuk gumpangumpalan yang akan mengendap di dasar wadah. Jika volume PAC yang ditambahkan terlalu banyak, maka apabila kotoran yang diikat sudah mengendap seluruhnya, PAC akan menjadi pengotor dalam air tersebut.

Data perhitungan dosis PAC Optimum

Volume air sampel : $500 \mathrm{~mL} \quad$ (a)

Volume PAC : $10 \mathrm{~mL} \quad$ (b)

Dosis PAC $\quad: 10 \mathrm{~g} / \mathrm{L}$

Dosis PAC Optimum (DPACO)

$\mathrm{DPACO}=\frac{b x c}{a} \quad=\frac{10 m L x 10 \mathrm{~g} / \mathrm{L}}{500 \mathrm{~mL}}=0,2 \mathrm{~g} / \mathrm{L}$

$$
=200 \mathrm{mg} / \mathrm{L}(200 \mathrm{ppm}) \text {. }
$$

Dari hasil perhitungan kadar PAC optimum percobaan adalah 200 ppm yaitu dengan menambahkan $10 \mathrm{~mL}$ PAC ke dalam $500 \mathrm{~mL}$ air. Hasil penelitian Agung (2006) menjelaskan kondisi terbaik untuk koagulan PAC dicapai pada konsentrasi $250 \mathrm{ppm}$ dengan menambahkan flukolan sebesar $12 \mathrm{~mL}$ per $500 \mathrm{~mL}$ sampel air. Hasil percoban yang dilakukan mendekati dengan hasil penelitian sebelumnya, maka dosis optimum PAC hasil percobaan dianggap dapat dipertanggungjawabkan.

\subsection{Pengujian Sampel Air Sungai Suko dengan Koagulan Kaporit}

Hasil pengujian pengolahan air sungai Suko dengan proses koagulasi dengan koagulan kaporit dapat dilihat dalam Tabel 4.

Tabel 4. Hasil pengujian dengan koagulan kaporit

\begin{tabular}{lllllll}
\hline Sampel & $\mathbf{1}$ & $\mathbf{2}$ & $\mathbf{3}$ & $\mathbf{4}$ & $\mathbf{5}$ & $\mathbf{6}$ \\
\hline pH awal & 6 & 6 & 6 & 6 & 6 & 6 \\
$\begin{array}{l}\text { Volume } \\
\text { tawas (mL) }\end{array}$ & 4 & 6 & 8 & 10 & 12 & 14 \\
$\begin{array}{l}\text { Kejernihan } \\
\text { pH akhir }\end{array}$ & 1 & 2 & 6 & 4 & 5 & 3 \\
\hline
\end{tabular}

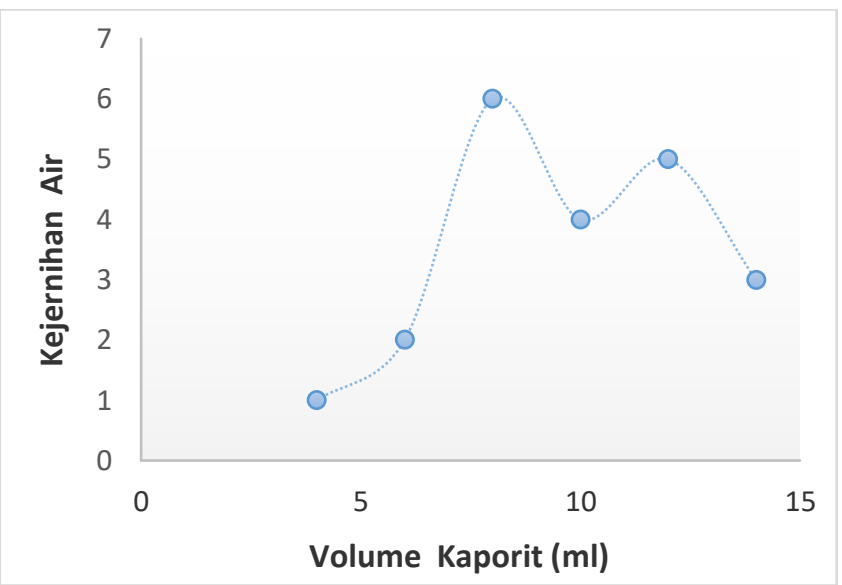

Gambar 3. Hubungan antara kadar kaporit dengan kejernihan air.

Gambar 3 dapat dilihat bahwa dengan penambahan volume kaporit $8 \mathrm{~mL}$ dihasilkan tingkat kejernihan dengan angka 6 , ini menunjukan bahwa penambahan koagulan kaporit $8 \mathrm{~mL}$ menghasilkan kejernihan air yang maksimal, data ini dapat digunkan untuk menghitung dosis kaporit optimum.

Kaporit berfungsi untuk mengendapkan kotoran dengan cara mengikat kotoran terlebih dahulu membentuk gumpangumpalan yang akan mengendap di dasar wadah. Jika volume kaporit di tambahkan terlalu banyak, maka apabila kotoran yang diikat sudah mengendap seluruhnya, kaporit akan menjadi pengotor air tersebut.

Data perhitungan Dosis Kaporit Optimum

Volume air sampel : $500 \mathrm{~mL} \quad$ (a)

Volume kaporit $: 8 \mathrm{~mL}$

Dosis kaporit $\quad: 10 \mathrm{~g} / \mathrm{L}$

Dosis Kaporit Optimum (DKO)

$\mathrm{DKO}=\frac{b x c}{a} \quad=\frac{8 m L x 10 g / L}{500 m L}=0,16 \mathrm{~g} / \mathrm{L}$

Dari hasil perhitungan kadar kaporit optimum percobaan adalah 160 ppm yaitu dengan menambahkan $8 \mathrm{ml}$ kaporit ke dalam $500 \mathrm{~mL}$ air. Hasil penelitian Putra et.al (2009) menjelaskan kondisi optimum untuk koagulan kaporit dicapai pada konsentrasi 50 ppm dengan menambahkan kaporit $4 \mathrm{~mL}$ ke dalam $300 \mathrm{~mL}$ air. Hasil percobaan yang dilakukan mendekati dengan hasil penelitian sebelumnya. 


\subsection{Analisa Perbandingan Koagulan}

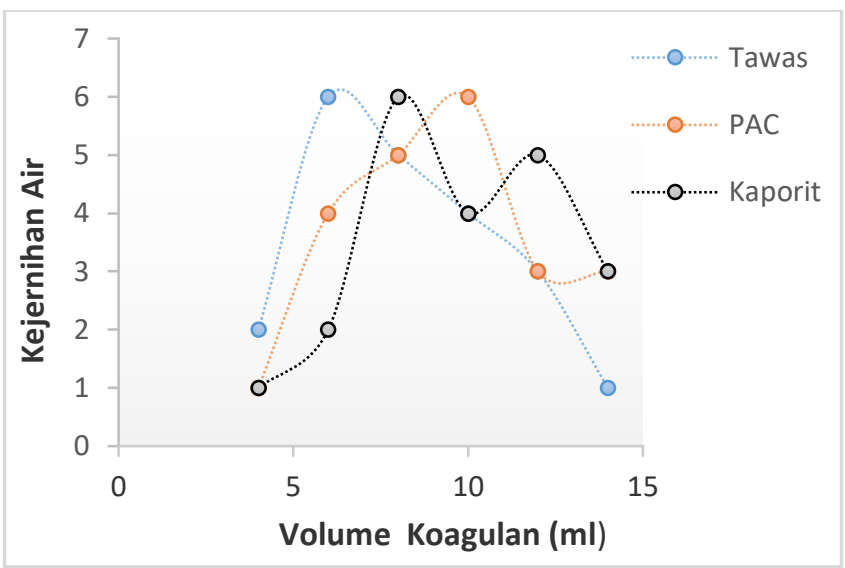

Gambar 4. Hubungan antara volume koagulan dengan kadar kejernihan air

Gambar 4 dapat dianalisa bahwa dengan penambahan koagulan tawas $6 \mathrm{~mL}$ ke dalam $500 \mathrm{ml}$ air sungai Suko mampu menjernihkan air Sungai Suko dengan tingkat kejernihan (6) bila dibandingkan dengan pemberian koagulan kaporit $8 \mathrm{~mL}$ ke dalam $500 \mathrm{ml}$ air sungai Suko, dan pemberian koagulan PAC sebanyak $10 \mathrm{~mL}$ ke dalam $500 \mathrm{~mL}$ air sungai Suko. Hal ini menunjukkan bahwa pemberian koagulan tawas lebih sedikit dibandingkan pemberian koagulan yang lain.

Setiap jenis koagulan memiliki kadar optimum yang berbeda, hal ini dikarenakan setiap koagulan memiliki kemampuan dalam mereduksi polutan dalam air yang berbeda-beda, sehingga dalam pencapaian tingkat kejernihan air pun berbeda.

Ketika koagulan direaksikan dengan air limbah, partikelpartikel koloid yang terdapat dalam limbah tersebut akan membentuk agregasi atau penggabungan partikel kecil untuk membentuk partikel yang lebih besar, sebagai akibat dari adanya perbedaan muatan antara partikel koloid dengan koagulan, pengadukan lambat menyebabkan flok-flok tersebut akan saling bergabung membentuk flok yang lebih besar. Flok-flok yang terbentuk mempunyai berat molekul yang lebih besar dari molekul air, sehingga flok tersebut akan dengan mudah mengendap. Penambahan koagulan dengan dosis yang tepat akan dapat menurunkan kadar polutan yang ada di dalam air (Risdianto, 2007).

Hasil analisa perbandingan koagulan menunjukkan bahwa koagulan tawas memberikan hasil signifikan dibandingkan kedua koagulan lainnya, dengan diperoleh dosis tawas optimum $120 \mathrm{mg} / \mathrm{L}$ untuk pengolahan proses koagulasi air Sungai Suko. Bila dibandingkan dengan penelitian sebelumnya, hasil dari penelitian ini hampir sama dengan penelitian yang dilakukan oleh Agung (2006) yang berkesimpulan bahwa hasil analisa pengolahan air saluran pematusan Kebon Agung dengan menggunakan instalasi pengolahan air mini didapatkan bahwa untuk jenis koagulan tawas ini mempunyai kecenderungan yang lebih baik bila dibandingkan dengan koagulan PAC.

\section{Kesimpulan}

Dari penelitian ini didapatkan kesimpulan bahwa pengolahan air sungai Suko menjadi air bersih dengan metode Jar Test menggunakan kogulan tawas dengan dosis optimum $120 \mathrm{mg} / \mathrm{L}$, koagulan kaporit dengan dosis optimum $160 \mathrm{mg} / \mathrm{L}$, dan koagulan PAC dengan dosis optimum 200 $\mathrm{mg} / \mathrm{L}$. Koagulan tawas lebih cocok untuk menjernihkan air sungai suko dibandingkan dengan koagulan PAC dan kaporit, dengan dosis tawas optimum $120 \mathrm{mg} / \mathrm{L}$.

Penelitian ini masih memerlukan proses lanjutan yaitu proses filtrasi atau penyaringan dengan metode saringan pasir cepat. Pengujian kekeruhan air masih hanya dengan visualisasi yaitu mengukur dengan angka tingkat kejernihan skala 1 sampai 6 , oleh karena itu dibutuhkan pengukuran tingkat kekeruhan yang lebih valid.

\section{Ucapan Terima kasih}

Peneliti mengucapkan terima kasih kepada Universitas Widya Dharma Klaten atas dana yang diberikan melalui skim Penelitian Intern Perguruan Tinggi tahun 2020, dan tak lupa semua pihak yang ikut membantu dalam penelitian ini.

\section{Daftar Pustaka}

Agung, T. (2006). Penentuan Dosis Optimum Koagulan untuk Mengolah Air Kali Kebon Agung menjadi Air Bersih. Jurnal Rekayasa Perencanaan. Vol. 3. No.1.

Budiman, A., Wahyudi, C., Irawati, W., Hendarso, H. (2008). Kinerja Koagulan Poly Alumunium Chloride (PAC) dalam Penjernihan Air Sungai Kalimas Surabaya Menjadi Air Bersih. Widya Teknik Vol. 7. No. 1. 25-34.

Eckenfelder Jr, W. Wesley. (2000). Industrial Water Pollution Control 3th ed. Singapore: Mc Graw Hill Book Co.

Husaini, Cahyono, S.S., Suganal, Hidayat K.N. (2018). Perbandingan Koagulan Hasil Percobaan dengan Koagulan Komersial Menggunakan Metode Jar Test. Jurnal Teknologi Mineral dan Batubara Vol. 14, No. 1. $31-45$.

Peraturan Menteri Kesehatan Republik Indonesia No.416/Menkes/Per/IX/1990 untuk Air Bersih.

Putra, S., Randjono, S., Arifiansyah, T. (2009). Optimasi Tawas dan Kapur untuk Koagulasi Air Keruh dengan Penanda I-131. Seminar Nasional V SDM Teknologi Nuklir ISSN 1978-0176. Sekolah Tinggi Teknologi Nuklir BATAN. Yogyakarta.

Risdianto, D. (2007). Optimasi Proses Koagulasi Flokulasi untuk Pengolahan Air Limbah Industri Jamu (Studi Kasus PT. Sido Muncul). Thesis Magister Teknik Kimia. Program Pasca Sarjana Universitas Diponegoro, Semarang.

SNI 19-6449-2000. Metode Pengujian Koagulasi-Flokulasi dengan Jar Test. Badan Standarisasi Nasional.

Sutrisno, T. (2010). Teknologi Penyediaan Air Bersih. PT. Rineka Cipta. Jakarta. 
Wan Usman. (2000). Air Sebagai Sumber Daya Alam dan Aspek Ekonominya. Jurnal No.1. Universitas Terbuka.

Wathoni, A.Z., Ulfindrayani, I.F., Hidayat, K. (2020). Pengaruh Penambahan Flokulan dan Koagulan
Menggunakan Metode Jar Test terhadap Kualitas Air Baku. Jurnal Industry Xplore Vol.5. No.2. 